\title{
Effective nursing care of children and young people outside hospital
}

\author{
Lisa Whiting and colleagues report on a study to assess how staff and \\ service users perceive out-of-hospital provision, with a view to identifying the \\ pre- and post-qualification education needs of community children's nurses
}

\section{Open access}

Correspondence

I.whiting@herts.ac.uk

Lisa Whiting is professional lead in children's nursing for the University of Hertfordshire

Chris Caldwell is dean of healthcare professions at Health Education, North Central and East London

Mary Donnelly and Debbie Martin are senior lecturers in children's nursing, University of Hertfordshire

Mark Whiting is WellChild professor of community children's nursing, University of Hertfordshire, and a member of Nursing Children and Young People's editorial advisory board

Date of submission November 12014

Date of acceptance April 12015

Peer review

This article has been subject to open peer review and checked using antiplagiarism software

\section{Author guidelines}

journals.rcni.com/rl ncyp-author-guidelines

\begin{abstract}
Aim To assess the preparation required to ensure a workforce of nurses who can provide high quality out-of-hospital services for children and young people.

Methods Using mixed methods, questionnaires were sent to young people and community children's nursing teams, interviews were conducted with academic staff and clinical nurses, and focus groups were undertaken with pre-registration children's nursing students.

Findings Nurses' communication skills and clinical abilities were most important to

young people. There is a range of opinions about optimum out-of-hospital clinical experience.

Pre- and post-qualification education and recruitment in this area, therefore, need attention.

Conclusion Out-of-hospital care presents problems, but is developing rapidly. Adequate, updated training, supervision and resources are needed.

\section{Keywords}

Child health, community children's nursing, out-of-hospital care, paediatrics, workforce planning
\end{abstract}

THIS ARTICLE presents an exploratory study that was financed and commissioned by Health Education, North Central and East London (NCEL), and the local education and training board (LETB); it was undertaken by the University of Hertfordshire between February and August 2014. The research was funded to explore the educational needs of the nursing workforce in relation to out-of-hospital care for children and young people in the UK. The data will be used to inform the development of service provision.

\section{Background}

In 1959, in its seminal report on the Welfare of Children in Hospital (Ministry of Health 1959), the Platt Committee identified the potential benefits for children of redirecting services from hospital and to the community.

Since the publication of the report, there has been a reduction of about $75 \%$ in the total number of children's hospital beds in the UK (Health and Social Care Information Centre 2013). At the same time, there has been an increase in the amount and range of care being provided in out-of-hospital settings. These shifts have significantly affected the preparation and training of healthcare staff.

\section{Literature review}

Whereas evidence to demonstrate the benefits of delivering more community-oriented health provision for children remains elusive (Parker et al 2002, 2011), a succession of Department of Health (DH) reports have supported the need to expand and develop the community children's nursing (CCN) workforce to deliver care closer to home (DH 1991, 2004, 2011, 2013).

Further endorsement has been provided by the Royal College of Nursing (RCN) $(2000,2008)$ and the Royal College of Paediatrics and Child Health (RCPCH) (2011), as well as the DH's commissioned review of children's palliative care (Craft and Killen 2007), Sir Ian Kennedy's review of children's health services provision (Kennedy 2010), and the Children and Young People's Health Outcomes Forum (DH 
2012). The forum specifically recommended that Health Education England addresses workforce education, training and development to 'refocus service provision at home or closer to home'. Other DH documents confirm the commitment to community-based services across the age spectrum, as well as indicating the need to underpin this with an appropriately educated and adequate workforce (DH 2014).

In this study, out-of-hospital care is defined as including 'all those services provided in community settings such as in your home by community nurses, at your GP's surgery and in health centres' (NHS North West London 2012).

\section{Aim}

The aim was to answer the research question posed by Health Education, NCEL, and LETB: 'What education, preparation and development is required to ensure a workforce of nurses who have the requisite knowledge, skills and professional attributes to meet the healthcare service needs of the CYP [children and young people] population in the LETB geography?' (Health Education, NCEL 2014).

\section{Methods}

The study was exploratory and focused on the out-of-hospital environment, although health visiting and school nursing were excluded. A mixed methods approach was adopted because this offered the opportunity to collect quantitative as well as qualitative data (Tashakkori and Creswell 2007). This was important for addressing fully the research question, because quantitative data could be complemented with the results of the qualitative method. The following data collection strategies were used:

Quantitative: questionnaires (with one open question) were sent to young service users and the CCN teams in the NCEL area.

Qualitative: individual interviews were conducted with clinical nurses working in NCEL out-of-hospital children's settings, and with academic staff associated with the pre-registration children's nursing programme in each of the four higher education institutions (HEIs) in the NCEL area. Focus groups were undertaken with pre-registration children's nursing students. Young people were specifically asked about the provision of out-of-hospital health care, their perceptions about it and the skills required by nurses working in these settings. Clinical nurses, HEI academics and pre-registration children's nursing students were questioned about their experiences relating to out-of-hospital clinical placements and the educational preparation required to work in these environments.

Recruitment Young people, aged 16-23 years, were recruited to the study via established youth advisory panels - RCPCH and the National Youth Agency (NYA). Each panel employed an adult co-ordinator, and it was agreed that the most appropriate participation method for the young people would be through a questionnaire.

The sample of nurses was recruited via two routes. First, the RCN directory of CCN services (RCN 2010) identified 11 teams based in the NCEL area. Second, two senior practitioners working in NCEL out-of-hospital settings were approached and asked to identify clinical nurses whom the research team could contact to request their participation.

To recruit the academic staff and pre-registration children's nursing students affiliated to the four HEIs in the NCEL area, permission was sought and granted from each dean of school/head of department.

\section{Data collection tools}

Questionnaires Two questionnaires were developed by the project team to gather quantitative data, and a small amount of qualitative information, from two groups (young people and the CCN teams). The panel co-ordinators distributed information sheets and questionnaires to the young people, returning those completed to the research team $(\mathrm{n}=14)$. The leader of each of the $11 \mathrm{CCN}$ teams was sent an information sheet and a questionnaire; seven completed forms were returned. Informed implied consent was obtained from both groups.

Questions to the young people included where they had received care and what was important to them in out-of-hospital care. The CCN participants were asked if pre-registration students were prepared adequately for placements and how much time post-registration $\mathrm{CCN}$ students were able to spend gaining clinical experience with the team.

Interviews and focus groups Individual semi-structured interviews were undertaken with two academic staff from each of the four HEIs and six clinical nurses working in out-of-hospital settings.

Focus groups were conducted with pre-registration children's nursing students in three of the four HEIs $(n=14)$; the lack of student participation in the fourth HEI was due to a combination of staff sickness and the student placement pattern. Guidelines for the conduct of the focus groups were drawn up; the procedures for the role of the facilitator before, during and after the focus group were set out; the 'ground rules' for participants were outlined; 
and there was also a set of 'prompt' questions to maintain consistency and maximise data gathering.

Written and verbal consent was gained before undertaking the interviews and focus groups; all were conducted by members of the research team and took place in the participants' work/HEI environment. Each interview or focus group (19-64 minutes' duration) was recorded using a digital audio recorder.

To assist confidentiality, all participants were allocated a code that was used when reporting findings, and all information relating to data collection was kept in hard copy, as well as on an encrypted USB memory stick, and stored in a locked cabinet.

Each participant and HEI was allocated a code to maintain confidentiality: HEIs and students were assigned a letter, while clinical nurses and academic staff were given a number.

Analysis of data Fundamental to a mixed-methods approach is the integration of qualitative and quantitative findings. Authors have suggested that this can be achieved through merging, embedding or connecting (Creswell and Plano Clark 2007, Palinkas et al 2011). This study connected the qualitative and quantitative findings so that a whole picture was formed.

Descriptive statistics were used to summarise quantitative data from questionnaires, and the results summarised. Each interview and focus group was transcribed into a table in Microsoft Word and then checked for accuracy of transcription against the recordings. Braun and Clarke's (2006) six-stage approach was used to guide thematic analysis.

Ethical considerations Approval to conduct all aspects of the study was granted by the University of Hertfordshire health and human sciences ethics committee.

\section{Findings}

Young people The most important aspects of health care for the 14 young people related to being involved in decisions ( $\mathrm{n}=14$ ), being cared for by professionals with the requisite knowledge and skills $(\mathrm{n}=13)$, being listened to $(n=13)$, having confidentiality maintained $(n=13)$, and having treatment explained in an understandable manner ( $\mathrm{n}=12)$, so nurses' communication skills and clinical abilities were ranked highly. Other aspects, such as waiting times $(n=9)$ and the gender of the nurse $(n=5)$, were perceived as less crucial.

The questionnaires revealed that, although ten young people had experienced out-of-hospital care, there was more confidence in health care provided in a hospital setting. Unfortunately, the young people's experiences of health care in a range of in-hospital and out-of-hospital settings had not always been positive.

One participant said: 'Management very poor - all box ticking with times that need to be met, shuffled around and not listened to as a human' (NYA, female, aged 23 years). Another commented: 'My experience of health care has been mostly negative, as I don't feel listened to or understood. I feel frustrated with no answers and have given up' (NYA, female, aged 21 years).

However, another participant who had a long-term health problem offered a different perspective: 'I have found being able to access care at home, or in a non-hospital setting, to be invaluable to improving my health' (RCPCH, female, aged 23 years).

\section{Community children's nurses The $\mathrm{CCN}$ teams} revealed that they were providing diverse services for children and young people with acute and short-term conditions, as well as managing more complex and long-term health needs. Four of the seven teams who responded indicated that there were intentions to expand their services.

Only one team reported having a pre-registration children's nursing student for a final 12-week 'sign-off' placement. Across the seven CCN teams, eight staff members had been seconded to undertake the CCN specialist practitioner qualification in the past five years, three teams had never seconded anyone and one team had seconded one. Of particular note was the fact that one team, for the first time in five years, had not seconded anyone to the programme. The findings suggest that the numbers of post-registration students undertaking the CCN specialist practitioner qualification was not only small but was declining.

Many of the staff working in the CCN teams were employed in bands 6 and 7, with only two teams indicating that they had employed a band 5 nurse on registration.

Clinical nurses Those interviewed had between 1.5 and 16 years' experience (mean eight years) of working in an out-of-hospital environment. Job roles/titles were variously described as advanced nurse practitioner, clinical nurse specialist, generic CCN sister, service manager, team leader and head of care. All the clinical nurses held a children's nursing qualification that was registered with the Nursing and Midwifery Council. Although all interviewees reported that they had completed one or more post-registration clinical courses, none had undertaken the CCN specialist practitioner qualification.

The participants offered a range of views on what they considered to be out-of-hospital care, 
including the identification of a variety of health professionals and clinical settings. There was general agreement that an approximately equal balance of out-of-hospital and hospital experiences would be appropriate for pre-registration children's nursing students, and that the provision of such a balance would increase the likelihood that they would want to work in the community after they qualified.

However, it was acknowledged that the experience needs to be relevant, clinical and commensurate with the students' learning needs.

It was suggested that more time should be spent in the community in academic years 2 and 3 of the pre-registration children's nursing programme, after students had 'gained some knowledge from the general paediatric side of things' (clinician 3).

Further exploration was undertaken in relation to learning outcomes for students on placement. There was strong support for involving students in the formulation of their own learning outcomes in the first few days of a placement, with participants acknowledging the importance of building on prior learning and experience.

The clinical nurses were asked to consider opportunities for newly qualified children's nurses to work in out-of-hospital environments. A view emerged that such posts would present substantial challenges, for example:

- 'Need a bit of time to consolidate their clinical skills' (clinician 2).

'If you are working in the community, you're working independently and autonomously, and you really need a level of experience to be able to make some clinical decisions' (clinician 4).

'You really need the inpatient grounding to understand the conditions and the unwell child before seeing them in the community... I think a minimum of 18 months' experience on an inpatient ward' (clinician 5).

In particular, the clinical nurses recognised the need for mentorship and support to be provided for the newly qualified nurse, which presented some difficulties. Comments include:

- 'Newly qualified nurses need a lot of support, say for six months or a year, to prepare for the community' (clinician 3).

'It's really a matter of whether you can give the amount of support to a newly qualified nurse' (clinician 4).

'We don't have a mechanism to support newly qualified nurses' (clinician 5).

Academics The HEI staff identified a range of out-of-hospital clinical experiences. However, discussions were primarily centred on $\mathrm{CCN}$ experiences. It was evident that these academics thought that there was limited availability of out-of-hospital clinical experiences for pre-registration children's nursing students, with concern expressed about student placement capacity.

The findings also revealed marked differences, in terms of the out-of-hospital clinical experiences gained by children's nursing students, between HEIs and across cohorts within each HEI. In addition, it was reinforced that it is unusual for these students to undertake a 12-week sign-off placement in an out-of-hospital clinical area. One said: 'Currently, all the sign-off placements are in acute units because of availability and being unable to place students for 12 weeks in a community setting' (HEI W, participant 2).

The academic participants thought that the students did not always understand the value of out-of-hospital clinical experiences, and that mentors did not always appreciate the involvement that pre-registration children's nursing students could have in relation to participating in out-of-hospital nursing care.

'On the wards nurses seem to have a better understanding of what students require, whereas in the community I sometimes feel that they have much higher expectations or they aren't able to provide quite the same ability to enable students to learn. It's a lot more observation, rather than enabling them to start providing care as a student themselves' (HEI W, participant 1).

'People are risk averse, so they don't let them [students] do some things that perhaps they could easily be doing in the community [that] they're more than competent to do' (HEI Z, participant 1).

\section{Pre-registration children's nursing students}

Students' expectations of nursing before starting their programme of study varied, with some not appreciating fully that they would be gaining clinical experiences in out-of-hospital areas. Comments included:

'I really didn't know what to expect when

I started' (HEI X, second-year student G).

- 'To start with, you question, because you think of nurses in hospital, so to start off with you think, "why am I here?" Then after a couple of hours or maybe a day you realise that there's a lot more to nursing than just being in a hospital' (HEI Y, first-year student).

The students were able to identify a diverse range of out-of-hospital services, such as health visiting, school nursing, day surgery units, Sure Start centres, community adolescent mental health services, walk-in centres, GP surgeries and outpatient departments. Despite this, during the focus group discussions, 'community' was consistently used to refer to school 
nursing, health visiting and $\mathrm{CCN}$ and 'clinical' to refer to hospital-based services. For example: 'Personally, I think it's good to have a mixture, because I enjoyed my experiences. I've had quite a few community and quite a few clinical, and the variety has been good. I wouldn't say I'd want more of one and less of the other. I just want a mix, or more of a balance' (HEI Y, second-year student O).

Students perceived that HEIs provided preparation for clinical practice, but this could be limited in relation to out-of-hospital experiences. Students demonstrated a self-motivated approach to preparation and emphasised the importance of their peers' knowledge: - 'It's a lot about the knowledge from your peers... [they] were maybe the first person you would go to, to just say this has happened, did it happen to you? And you would have that support network within your cohort, which I think is the main thing, because you're with them for three years' (HEI Y, third-year student W).

'The best preparation has come from talking to peers that have actually been there'

(HEI X, second-year student Q).

Students also recognised their responsibility to identify and develop learning opportunities/ outcomes themselves. For example, when asked about the learning outcomes that they were expected to achieve, the students appreciated that they needed to fulfil certain criteria, but that there was also an understanding that specific learning outcomes needed to be formulated in relation to a particular placement area. Some of these were self-identified, others provided by the placement but, most commonly, there was discussion with their mentor:

'I did mine with my mentors. I always sit down with my mentors and say, "what can I do on this placement?"... I think that speaking to the mentors actually helps you formulate the objectives' (HEI X, second-year student U).

\section{Discussion}

Harvey and McMahon (2008), authors of Shifting the Balance of Health Care to Local Settings, a King's Fund-commissioned report, observed: 'The scale of workforce development, organisational development and education and training needed to underpin new ways of working should not be underestimated.'

The NHS Confederation (2012) concurs that one of the challenges in making out-of-hospital care a reality for children, young people and adults is the need to ensure that appropriate education and training is in place to provide staff with the necessary expertise. The young people who participated in the study described some of the attributes they thought were fundamental to high quality nursing care: communication skills and clinical abilities were most highly ranked. This is particularly noteworthy because some of the young people commented on less than positive experiences of out-of-hospital care and indicated that communication skills - essential in good health care - could be limited. This would suggest that nurse education programmes may need to focus more overtly on communication in the specific context of out-of-hospital settings.

Most student participants in the focus groups had undertaken a health visiting or school nursing placement, whereas their experience in other out-of-hospital services was limited. For example, only one had had a placement in a walk-in centre and not one mentioned general practice nursing. This could be important, because it has been suggested that students' clinical learning opportunities frequently influence their choice of employment at registration (Morrow 2009). Therefore, in education and preparation, timely consideration of the out-of-hospital clinical experiences undertaken by pre-registration children's nursing students, particularly in relation to the type, duration and the stage in their programme of study, is essential.

The provision of more opportunities for students to undertake their final 12-week sign-off clinical experience in an out-of-hospital setting would offer more opportunity to improve vital clinical and communication skills. However, this study has also

\section{References}

Braun V, Clarke V (2006) Using thematic analysis in psychology. Qualitative Research in Psychology. 3, 2, 77-101.

Craft A, Killen S (2007) Palliative Care Services for Children and Young People in England. Department of Health, London.

Creswell J, Plano Clark V (2007) Designing and Conducting Mixed Methods Research. Sage Publications, London.

Department of Health (1991) The Welfare of Children and Young People in Hospital. DH, London.

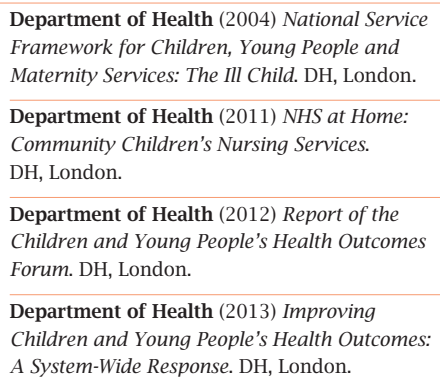

Department of Health (2004) National Service Framework for Children, Young People and Maternity Services: The Ill Child. DH, London.

Department of Health (2011) NHS at Home: Community Children's Nursing Services. DH, London.

Department of Health (2012) Report of the Children and Young People's Health Outcomes Forum. DH, London.

Department of Health (2013) Improving

Children and Young People's Health Outcomes:

A System-Wide Response. DH, London.

Department of Health (2014) Delivering High Quality, Effective, Compassionate Care: Developing the Right People with the Right Skills and the Right Values. A Mandate from the Government to Health Education England: April 2014 to March 2015. DH, London.

Harvey S, McMahon L (2008) Shifting the Balance of Health Care to Local Settings. The Seesaw Report. King's Fund, London.

\author{
Health and Social Care Information Centre \\ (2013) Hospital Episode Statistics: Admitted \\ Patient Care - 2012-23. tinyurl.com/ovydprl \\ (Last accessed: May 20 2015.) \\ Health Education, North Central and East \\ London (2014) Delivering Effective Nursing \\ Care to Children and Young People Outside \\ a Hospital Setting - Outline Bid. (Unpublished) \\ Health Education, NCEL, London. \\ Kennedy I (2010) Getting It Right for Children \\ and Young People: Overcoming Cultural Barriers \\ in the NHS so as to Meet Their Needs. DH, London.
}


highlighted some resistance in the out-of-hospital workforce, particularly in CCN teams, to the employment of newly qualified children's nurses. This is a significant concern.

For example, staff do not always perceive that nursing students, at the point of registration, have the requisite knowledge and skills to work in an out-of-hospital setting. This could be remedied by not only inviting community staff across a range of settings to be involved in developing pre-registration children's nursing curricula, but facilitating and valuing the contribution these clinicians can make to student learning throughout the undergraduate programme. In addition, it is timely to consider the out-of-hospital clinical experiences available for students and assess whether these could be developed further.

To further address training needs, consideration should be given to the post-registration education of staff. This training should enable them to provide high quality evidence-based care to a range of children and young people in an out-of-hospital setting. It needs to include their own professional development and that of the pre-registration children's nursing students they mentor, and cover the acquisition of up-to-date information about out-of-hospital clinical activities and skills.

Finally, a more consistent use of terminology is recommended. Many documents now use the term 'out of hospital', but this is not a phrase that was used in the interviews and focus groups. Consequently, 'hospital' and 'out of hospital' descriptors are better used from the point of student selection and recruitment, and throughout planning, preparation and evaluation of student clinical experiences. Words such as 'acute', 'community' and 'clinical' do not always reflect service provision accurately.

Limitations Data collection was undertaken in the NCEL area, with the exception of the questionnaires sent to the young people. Therefore generalisations are not possible, although the findings may have applicability to other geographical areas.
Consultation with young people took place, but the age range was limited. Although the information gained is valuable, it must be acknowledged that the views expressed may not be wholly representative of other young people.

Students from each of the four HEIs in the NCEL area were invited to participate in the project. Those who took part may have done so because they had a specific interest in out-of-hospital experiences and may envisage their career developing in an out-of-hospital environment, which would bias the results.

Interviews with clinical nurses were conducted, but it is recognised that the sample and range of posts held by the participants were limited and may not be representative.

\section{Conclusion}

If out-of-hospital care is to be enhanced,

the commitment and expertise of those working directly with children and their families are crucial. The future nursing workforce and its management need to respond to out-of-hospital care policy at local and national levels to ensure adequate service provision. This will necessitate nurses who work in out-of-hospital settings taking a proactive and engaged approach to policy. It is anticipated that the findings from this research will provide data with the potential to inform planning, so that out-of-hospital care for children and their families can continue to be developed and improved.

\section{Implications for practice}

Increased out-of-hospital care requires appropriate training and supervision of staff at all levels

Young out-of-hospital clients find the communication and clinical skills of nurses most important

There is a need for more pre-registration out-of-hospital placements and more children's community nurses to take the specialist qualification Organisational development should underpin the above
Online archive

For related information, visit our online archive and search using the keywords

Conflict of interest

None declared
Ministry of Health (1959) The Welfare of Children in Hospital, Platt Report. HMSO, London.

Morrow S (2009) New graduate transitions: leaving the nest, joining the flight. Journal of Nursing Management. 17, 3, 278-287.

NHS Confederation (2012) Making Integrated Out-of-Hospital Care a Reality. NHS Confederation, London.

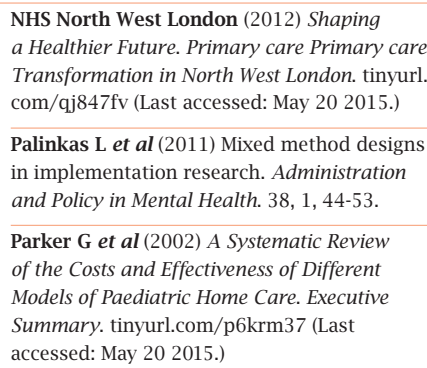

NHS North West London (2012) Shaping a Healthier Future. Primary care Primary care Transformation in North West London. tinyurl. com/qj847fv (Last accessed: May 202015. Palinkas L et al (2011) Mixed method designs in implementation research. Administration and Policy in Mental Health. 38, 1, 44-53.

Parker G et al (2002) A Systematic Review of the Costs and Effectiveness of Different Models of Paediatric Home Care. Executive Summary. tinyurl.com/p6krm37 (Last accessed: May 202015.

Parker G et al (2011) Evaluating Models of Care Closer to Home for Children and Young People Who Are Ill. Final report. NIHR Service Delivery and Organisation Programme, University of York, York.

Royal College of Nursing (2000) Children's Community Nursing: Promoting Effective Teamwork for Children and their Families. RCN, London.

Royal College of Nursing (2008) A Child's Right to Care at Home. RCN, London.
Royal College of Nursing (2010) Directory of Community Children's Nursing Services. RCN, London.

Royal College of Paediatrics and Child Health (2011) Facing the Future: A Review of Paediatric Services. RCPCH, London.

Tashakkori A, Creswell JW (2007) Editorial: the new era of mixed methods. Journal of Mixed Methods Research. 1, 1, 3-7. 